\title{
Needs, beliefs and barriers for contraceptive use among women in a low resource setting in Tamil Nadu: a qualitative study
}

\author{
Thacker S. Naveen', Sajitha M. F. Rahman'², Pavan Mukherjee ${ }^{3}$, Augustine ${ }^{3}$, \\ Kirubah V. David ${ }^{2}$, Ruby A. Pricilla ${ }^{1}$
}

\begin{abstract}
${ }^{1}$ Department of Community Medicine, Christian Medical College, Vellore, Tamil Nadu, India
${ }^{2}$ Department of Family Medicine, Christian Medical College, Vellore, Tamil Nadu, India

${ }^{3}$ Department of Medical Social Works, Christian Medical College, Vellore, India
\end{abstract}

Received: 28 August 2019

Accepted: 30 September 2019

\author{
*Correspondence: \\ Dr. Sajitha MF Rahman, \\ E-mail: sahuja100@hotmail.com
}

Copyright: (c) the author(s), publisher and licensee Medip Academy. This is an open-access article distributed under the terms of the Creative Commons Attribution Non-Commercial License, which permits unrestricted non-commercial use, distribution, and reproduction in any medium, provided the original work is properly cited.

\begin{abstract}
Background: The decline in fertility rate based on the National Health Profile is attributed to the choice of permanent sterilisation as the preferred method of contraception among Indian women. The uptake of spacing methods has declined over the years in many parts of India related to low awareness about options other than sterilisation. Hence understanding the needs, beliefs and barriers of women regarding contraceptive use can identify the factors behind their choice of contraceptive methods. This study aims to explore the needs, beliefs and barriers of women in using different methods of contraception in a low-resource area of urban Vellore, Tamil Nadu.

Methods: A qualitative study was conducted in three underserved areas of urban Vellore served by the secondary care hospital of a private academic institution. A descriptive qualitative method was chosen. Focus group discussion was carried out among study participants. Thematic analysis was used to analyse data.

Results: The need for contraceptive use was felt after completing the families determining the type of method chosen. Fear of impending side-effects of commonly available spacing methods of contraception limited their use. The results highlight the forceful use of intra-uterine device among study participants reflecting the incentive-based family planning services implemented in most Indian states.

Conclusions: Our study reinforces that neither the availability of contraceptives nor forceful implementation of policies will increase the utilisation of contraceptives. There is a need for community-based education on the indications, types and side-effects of reversible methods of contraception.
\end{abstract}

Keywords: Awareness, Beliefs, Barriers, Contraception, Focus group, Spacing methods

\section{INTRODUCTION}

The National Health Profile (NHP) 2018 documents the declining total fertility rate (TFR) among women of the reproductive age group in India. ${ }^{1}$ According to the NHP, the TFR in 12 Indian states including Tamil Nadu has fallen below two children per woman. Fertility decline has been primarily attributed to the choice of permanent sterilisation as the most preferred method of contraception among Indian women. While multiple factors including religious beliefs, education and occupation have been found to influence the choice of contraception, low socioeconomic conditions were documented as the major factor in choosing permanent sterilisation as the favourite method. ${ }^{2}$ 
The informed choice model of service delivery was introduced in the Indian Family Welfare Programme in 1998 to provide different options for family planning based on individual rights and needs. ${ }^{3}$ However, the availability of information on contraceptive methods and reproductive health among women of all social groups is found to be questionable. Women from low-resource communities are highly restricted by the availability of information on reversible methods of contraception. ${ }^{4}$ Their choice of contraception is further influenced by their trivial autonomy within their households. ${ }^{5}$

While health care facilities under the public-sector health care system in Tamil Nadu provide free access to different methods of spacing and sterilisation for women, the uptake of spacing methods has declined over the years in the state. ${ }^{6}$ This trend is related to low awareness about contraceptive options other than sterilisation in different parts of India. $^{7}$ Similar results have been documented in an earlier study conducted by the authors on the quality and satisfaction of antenatal care by midwives to low-risk pregnant women in underserved urban areas. ${ }^{8}$

Efforts to improve the uptake of reversible contraceptive methods must begin with an understanding of the problem in such settings. Understanding the ideas and opinion of women regarding contraceptive use can identify the factors behind their choice of different types of contraceptive methods. The results of this study can inform strategies for improving aware-ness and potentially increase reversible contraceptive utilisation among women in urban areas of the town. This study aims to explore the needs, beliefs and barriers of women in using different methods of contraception in a lowresource urban area of Vellore, Tamil Nadu.

\section{METHODS}

This study was conducted in three underserved areas of urban Vellore served by a team of physicians, community health nurse, community health workers and volunteers. This team is part of the secondary care hospital of a private academic institution providing health care for common diseases to people of all age groups in the nearby urban slums of Vellore. The population of five geographically defined areas of the urban slums are enumerated and served through weekly community clinics by the outreach team of the hospital. People of these areas access community clinics, physicians in other private health care systems and health facilities in the public health care system for their health care needs. Contraceptive services are available free of cost in the public health care system and for a nominal charge in the private health care systems.

A descriptive qualitative method was chosen for the study as there is minimal information on the needs and beliefs of contraceptive use among women in low resource setting in India. ${ }^{9}$ Qualitative description permits the presentation of facts with minimal interpretation. The unadorned description of events as told by participants related to contraceptive use was considered to be best reported by qualitative descriptive methodology.

Women of different age groups from different underserved urban areas were recruited to participate in the study. Each age group was chosen from one geographical area to maintain the homogeneity of the group. All the women had agreed to participate in another study by the same team on the survey of contraceptive use among women in a low-resource setting.

We used maximum variation sampling to ensure that diverse perspectives on contraceptive use are reported by the study participants. ${ }^{9}$ Maximum variation was applied at two levels:

\section{At the level of study participants, by selecting women of different age groups}

- Married women up to 25 years

- Married women between 26-35 years

- Married women between 36-45 years

At the level of geographical areas, three areas that differ in their population profile.

The authors are part of the outreach team that serve these areas. The authors worked with the community health workers and volunteers of the area to inform women who attended the clinic about the need for the study and invited them to participate in the study.

This study was approved by the Institutional Review Board and Ethics committee (No 11176) dated 28.02.2018.

Focus group discussion (FGD) was carried out among women who agreed to participate in the study. ${ }^{9}$ FGD was chosen as the unit of data collection to document a wide range of information on the needs and beliefs regarding contraceptive use. FGD was conducted among women of different age groups by the authors who are fluent in the regional language. An interview guide was prepared with open-ended questions and probes.

\section{The topics covered during the FGD include}

- Ideas and beliefs about contraception

- Awareness of different methods of contraception

- Factors favoring preferred contraceptive method

- Barriers in choosing different methods of contraception

- Sources of information and costs towards the use of contraception.

The interview guide was prepared in English, translated to Tamil and again back translated to English. One FGD 
was conducted in the secondary care hospital as the women of one area agreed to come to the hospital for FGD. The other two FGDs were conducted in the facility where clinics were run in their respective areas. Saturation of content was reached by the third FGD. FGD was conducted by the two authors that lasted for around 30 minutes, audio-recorded, transcribed and then analysed.

\section{Statistical analysis}

FGD transcripts were individually analysed by the authors using thematic analysis for emerging codes and the initial template was derived. Thematic analysis was used to identify themes recognizing the reasons for the low use of reversible methods of contraception. ${ }^{10}$ The final template was developed once the analysis of the transcripts of all FGDs was completed.

\section{RESULTS}

Major results that identified the choice of contraceptive methods among the study population are as follows:

\section{Need versus fear}

Many participants felt the need for contraceptive use when they completed their families. This specific need determined the type of method they eventually chose.

"People go for operation because they decide not to have any more children to take care of their lives and their children's lives".

The need for permanent sterilisation as the choice of contraception was defined on multiple occasions by the socio-economic contexts of families in low-resource settings.

"We have to plan it according to our situation, if we are below the poverty line, only one earning member of the family, then two children are enough, so that's why they go for sterilisation".

Besides, fear of impending side-effects of the commonly available spacing methods of contraception limited their use by participants.

"We may conceive after taking tablets or injections and if children may be affected by the side effects, so not to use it better. Like they told me, that their daughter had pus after inserting an intrauterine device (IUD), so we left the hospital without tell-ing anyone".

\section{Belief versus awareness}

Generally, sterilisation was widely believed to be the best option for contraception.
"If we do surgery, we'd have proper treatment, even if we have any complications like pain or difficulty, we can go immediately to the same doctor then we can go for the correct option. Operation is the best option".

Besides sterilisation, low awareness about other methods of contraception was expressed by most participants.

"We didn't know much about other methods...Also, we are scared of other methods...we didn't know about tablets".

Women attributed their low awareness about spacing methods to their context of early marriage.

"How will we know if we get married at 17 years of age? That we should take medicines to prevent pregnancy?"

\section{Individual versus system preferences}

Among the spacing methods, women expressed that the intrauterine device (IUD) was commonly recommended at health facilities, often inserted without patients' knowledge.

"For patients who undergo caesarean, IUD is inserted without permission but for those who have a normal delivery, they are asked permission. However, they don't allow us to leave without getting it inserted. They keep us for almost seven days for inserting the IUD”

However, some women believed IUD to be the better option and preferred it.

"Copper $\mathrm{T}(\mathrm{Cu} \mathrm{T})$ is the preferred method. I used it after the delivery of my first child, not to have a child immediately. I had it for $1-1 / 2$ years and later removed it. Then I conceived my second child. I think we can use it"

\section{Family versus community and religious beliefs}

Some participants stated the influence of family members in deciding on the time of sterilisation while the rest had minimal family influences.

"We need to get permission to proceed with our decision. Because if we have any problems in future, they'll question us. There will be problems if they come to know of it later. Mainly from husband and in-laws. It is easy to convince our husbands, but it's the mother-in-law to be convinced. They tell our husbands when we are not at home".

Participants expressed minimal influence on contraceptive use due to specific community beliefs. However, religious beliefs did persuade certain women to not to prefer sterilisation.

"If we go to areas with Muslims, many say that we don't want sterilisation due to our religious beliefs. According 
to the teachings of the Quran, they are not to under-go sterilisation procedures. They say that according to the Quran, we should not un-dergo sterilisation due to our religious beliefs. Within them, some undergo and some decline it. Some practice it sincerely while others are not".

\section{Lack of health education - major barrier}

Participants attributed their low awareness to lack of health education on contraceptive use.

"But nobody told us about tablets or injections. Maybe if somebody told us we would have tried it. We would have tried those things instead of $\mathrm{Cu} \mathrm{T}$ or tablets. We feel there is a risk with Copper T".

Physicians who provided antenatal care and delivered their babies were trusted by the participants as a reliable source of information on contraceptives.

"Only in hospitals. Not in the urban health centre or during home visits by nurses. Mostly we ask the doctor who delivered us. We expect them only because they'd know".

Even families or friends were not found to be adequate resources of information on contraceptive use.

"We didn't know much about contraceptive methods. Our parents didn't talk about it. So, we don't know much about it. We've never discussed much it. Only when you asked us personally about this, we came to know. Where do we go and talk about this? Some talk about it in friend's circle. Other than we don't talk about it to others".

\section{DISCUSSION}

The qualitative study explored the needs, beliefs and barriers of contraceptive use among women in lowresource settings of Vellore in Tamil Nadu. The study results indicate lack of health education on spacing methods of contraception as the major barrier to influence the choice and uptake of reversible contraceptives. Study participants rely on health facilities for family planning services. While IUD was widely preferred by health care professionals in such facilities, it created fear and false beliefs about the side effects of IUD, adversely influencing the overall uptake of other reversible methods of contraception among study participants. Such inequalities in health education on contraceptive use among women in rural parts of India are well documented in literature. ${ }^{4}$

The need for contraception, according to our study was perceived after completing the family that led to the choice of sterilization as the preferred method. This is similar to the data of National Family Health Survey (NFHS - IV). It confirms that female sterilization is the most common and preferred method of contraception in Tamil Nadu. However, $79 \%$ of women in Tamil Nadu are reported to have heard of family planning through electronic media or health workers and use health facilities as the primary source of information on contraception in urban and rural areas. ${ }^{6}$ Increased awareness of reversible methods of female contraception has been reported in studies done in other parts of India. ${ }^{11,12}$ However, these are surveys done among women attending health facilities in different parts of India and the comparability of such results to our study results is questionable.

This study highlights the forceful use of IUDs as the choice of contraception among study participants. This reflects the incentive-based family planning services in most Indian states in contradiction to the need-based approach necessary for improving contraceptive utilization in India. The health workers are to meet certain targets to promote contraceptive use and are awarded cash incentives for their services. ${ }^{13}$ This targetbased approach has been related to the coercive implementation of family planning services. ${ }^{14}$ Our study results emphasize that women are not supportive of such practices and responded by declining the spacing methods. In an ideal setting, women are to be educated on the types of contraceptives along with their side-effects to empower them to make an informed choice about contraceptive use.

The varied geographical landscape of India is built with traditional familial, cultural and religious beliefs as is evident by our study results on contraceptive use. The influence of family beliefs on contraceptive utilization is well documented in the literature. ${ }^{15}$ While home delivery of oral contraceptive pills, condoms and the emergency contraceptive pill are implemented by the government, health workers should aim to educate women and their family members on the need for contraceptive use and the feasibility of different contraceptive methods.

\section{CONCLUSION}

In resource-limited settings, neither availability of contraceptives nor forceful implementation of policies will increase the utilisation of contraceptives. Interventions at multiple levels to remove the fear and false beliefs related to contraceptive use are needed. Our study validates the need for community-based education on the indications, types and side-effects of reversible methods of contraception. Our study participants will be followed up with health education sessions to women and their families by community health workers and volunteers on the benefits of contraceptive use.

Funding: No funding sources Conflict of interest: None declared

Ethical approval: The study was approved by the Institutional Ethics Committee 


\section{REFERENCES}

1. Romero National Health Profile; 2018. Available at: http://www.cbhidghs.nic.in/WriteReadData/1892s/Be fore\%20Chapter1.pdf. Accessed on 25 th July 2019.

2. Oliveira IT, Dias JG, Padmadas SS. Dominance of sterilization and alternative choices of contraception in india: an appraisal of the socioeconomic impact. PLoS ONE. 2014;9(1):e86654.

3. Family Planning - A Right and Choice. Available at: https://www.jsk.gov.in/upload/report/2016/12/58525 6c2e8d98unfpa.pdf. Accessed on $25^{\text {th }}$ July 2019.

4. Singh A, Pallikadavath S, Ram F, Ogollah R. Inequalities in the advice provided by public health workers to women during antenatal sessions in rural India. PLoS ONE. 2012;7(9):e44931.

5. Moursund A, Kravdal O. Individual and community effects of women's education and autonomy on contraceptive use in India. Population Studies. 2003;57:285-301.

6. NFHS IV State Reports. Available at: http://rchiips.org/nfhs/NFHS-4Reports/TamilNadu. pdf. Accessed on $25^{\text {th }}$ July 2019.

7. Makade KG, Padhyegurjar M, Padhyegurjar SB, Kulkarni RN. Study of contraceptive use among married women in a slum in Mumbai. Nat $\mathbf{J}$ Com Med. 2012;3(1):41-3.

8. Pricilla RA, David KV, Siva R, Vimala TJC, Rahman SPMF, Angeline N. Quality of antenatal care provided by nurse-midwives in an urban health centre with regard to low-risk antenatal mothers. Ind J Comm Med. 2017;42(1):37-42.
9. Sandelowski M. Focus on research methods: whatever happened to qualitative description? Res Nurs Health. 2000;23:334-40.

10. Marshall MN. The key informant techniques. Family Practice. 1996;13:92-7.

11. Prateek SS, Saurabh RS. Contraceptive practices adopted by women attending an urban health centre. Afr Health Sci. 2012;4:416-21.

12. Sharma V, Mohan U, Das V. Sociodemographic determinants and knowledge, attitude, practice: a survey of family planning. J Family Med Prim Care. 2012;1(1):43-7.

13. Annual Report of Department of Health and Family Welfare 2016-17. Available at: https://mohfw.gov.in/sites/default/files/6201617.pdf

14. Target driven sterilization. Available at: https://www.hrw.org/news/2012/07/12/india-targetdriven-sterilization-harming-women. Accessed on $25^{\text {th }}$ July 2019.

15. Swamy HT, Bhanu M, Kumar BSN, Shivaraj NS. A qualitative study on the determinants of contraceptive use in a rural setting. Int $\mathrm{J}$ Comm Med Public Health. 2017;4(6):1943-50.

Cite this article as: Naveen TS, Rahman SMF, Mukherjee P, Augustine, David KV, Pricilla RA. Needs, beliefs and barriers for contraceptive use among women in a low resource setting in Tamil Nadu: a qualitative study. Int J Reprod Contracept Obstet Gynecol 2019;8:4332-6. 